\title{
CONTEXTO PEDAGÓGICO DE DON BOSCO. EN TORNO A LOS ANTECEDENTES DEL SISTEMA PREVENTIVO
}

\author{
Juan Pablo Conejeros M.*
}

\section{RESUMEN:}

El presente trabajo es una aproximación - desde la Teoría de la Educación y la Historia de la Pedagogía - al contexto pedagógico del siglo XIX en el que vivió Don Bosco con el propósito no sólo de poder apreciar las principales características de su propuesta educativa, sino además advertir posibles influencias de pedagogos anteriores y contemporáneos a él y que subyacen al sistema preventivo. Desde esta perspectiva se abordarán algunos aspectos teóricos/conceptuales y epistemológicos, así como algunos componentes socio/culturales e históricos del período en cuestión que faciliten el logro de los propósitos planteados.

Palabras clave: Sistema Preventivo - Contexto Pedagógico - Influencias Educativas.

\section{PEDAGOGICAL CONTEXT OF DON BOSCO. ABOUT THE BACKGROUND OF THE PREVENTIVE SYSTEM.}

\begin{abstract}
:
This paper is an approach - from the theory of Education a and Teaching History - the nineteenth-century pedagogic context which Don Bosco lived in order to appreciate not only the main features of his educational proposal, but also warn potential influences of past and contemporary educators to him and that underlying the preventive system. From this perspective we address some theorical/conceptual and epistemological as well as some component of social/cultural and historical period in question to facilitate the attainment of the proposals made.
\end{abstract}

Key Words: Preventive System- Pedagogical Context - Educational Influences

* Profesor de Teoría de la Educación y Teoría de la Enseñanza, Magister Artium en Historia, miembro del Grupo de Estudios Salesianos (GES), de la UCSH. 


\section{Introducción}

"Mi sistema consiste en no tener ninguno" Don Bosco

El presente trabajo es una aproximación, desde la Teoría de la Educación y la Historia de la Pedagogía, en torno a algunos aspectos tanto teóricos/conceptuales y epistemológicos, como hacia algunos componentes socio/culturales e históricos del contexto pedagógico del siglo XIX en el que Don Bosco desarrolló su propuesta educativa. La finalidad es poder advertir posibles influencias de pedagogos anteriores y contemporáneos a él que subyacen al sistema preventivo y, al mismo tiempo, apreciar sus principales características. No es un cotejo exhaustivo el que intentamos desarrollar aquí sino una aproximación preliminar a partir de la cual se puedan advertir, percibir y constatar ciertos vínculos, relaciones, paralelismos en sus planteamientos, en sus expresiones y argumentaciones, con las teorías y experiencias educativas de su "época".

Al abordar el estudio en torno al contexto pedagógico en el que vivió Don Bosco, y en el que surge su propuesta educativa, nos vemos obligados a situarnos de lleno, y conjuntamente, en dos planos como son: el de la Teoría de la Educación, por una parte, y el de la Historia de la Educación y la Pedagogía, por otra - que nos permitan, más propiamente, recorrer el camino de indagación y análisis que nos hemos propuesto aquí. Al iniciar esta búsqueda surgen necesariamente una serie de interrogantes que han de guiar nuestra indagación: ¿Cuáles son los antecedentes teóricos y prácticos, remotos y próximos, de la propuesta educativa de Don Bosco, el amico della giovennezza, el campeón de la Sociedad de la Alegría, el Maestro de Valdocco? ¿Dónde está situado el genio pedagógico de Don Bosco: en la elaboración teórico-discursiva de la educación? Y si fuere así, ¿Elaboró don Bosco una teoría de la educación? ¿Hay originalidad en Don Bosco? ¿De quién o de quienes se siente o se reconoce deudor en materia educativa? ¿Qué significan pedagógica y educativamente en él las figuras de un San Vicente de Paul, de un San Francisco de Sales, San Felipe Neri? ¿Cuáles son las teorías pedagógicas que la sustentan, los 
pedagogos más gravitantes y representativos? ¿Cuáles son los saberes pedagógicos que se han legitimado y difundido en su tiempo? ¿Cuáles son los modelos y sistemas educativos que surgen en la Europa decimonónica?; En qué pie se encuentra la educación y la pedagogía como saberes disciplinares desde la perspectiva epistemológica? ¿Cuál es el concepto de educación que se tiene culturalmente considerado en su tiempo?

Una primera aproximación que queremos abordar en este trabajo, con el propósito de dar cuenta de los objetivos formulados, está referida a los aspectos teórico/conceptuales y epistemológicos por los que transita la construcción del campo del saber disciplinar de la Educación y la Pedagogía en tiempos de Don Bosco, así como a los principales componentes socio/culturales e histórico/contextuales de la Europa del siglo XIX.

\section{Algunos alcances preliminares de orden teórico/ conceptual y epistemológico}

Respecto de lo anterior, es necesario señalar que hay que abordar un primer desafío conceptual, un primer escollo asociado al lenguaje educativo que se torna a veces algo impreciso, ambiguo, mal codificado. Nos referimos a la distinción entre Educación y Pedagogía que es preciso intentar abordar con la finalidad de poder establecer de entrada algún grado de precisión lingüística, claridad semántica y coherencia en su uso, que facilite a su vez el esfuerzo reflexivo y la comprensión de los planteamientos. Esta cuestión, por lo demás, no solo es una situación latente que incluso perdura hasta hoy. Ella ha afectado la "apropiación" conceptual del saber educativo, es una problemática que da cuenta de un saber en formación.

Sin duda que en estos complejos procesos de constitución epistémica nuevos códigos lingüísticos afloran en el horizonte de estos emergentes saberes. En los albores epistémicos de una nueva disciplina la mediación conceptual y la construcción de los nuevos códigos lingüísticos de referencia son reclamados y exigidos como 
parte sustantiva del desarrollo del discurso explicitador y explicativo. La mediación conceptual es clave en tanto el "logos" no sólo da a entender o significa directamente las ideas evocando las imágenes que son la representación interna de las cosas sino es un medio sustantivo entre el entendimiento y la realidad misma aprehendida. Se ponen en juego aquí, en último término, las posibilidades del conocimiento, de la verdad que sea capaz de manifestar.

¿Por qué nos podría importar esto al abordar un estudio acerca de la propuesta educativa de San Juan Bosco? Precisamente porque desde el punto de vista conceptual ( $\mathrm{y}$ en consecuencia, también epistemológico) hay que tener meridiana claridad respecto de estas distinciones requeridas para poder adentrarnos con propiedad en el conocimiento y en la comprensión de las ideas pedagógicas y experiencias educativas involucradas, en los planteamientos teóricos y prácticos vinculados a la propuesta donboscana que intentaremos pesquisar en su contexto. Es decir, es necesario, a nuestro juicio, tener claridad en este ámbito para poder diferenciar, por ejemplo, los aportes que proceden desde la bistoria de la pedagogía, de los aportes que vienen desde la bistoria de la educación (Luzuriaga, 1973; Ortega, 1984). Nos parece que es verdaderamente necesario poder establecer la diferencia entre la historia del "discurso" pedagógico, de la teoría pedagógica, y la historia acerca de la praxis, de "lo que hacían" tradicionalmente los maestros en las escuelas, en los espacios escolares, en los distintos ámbitos formativos (orfelinatos, hospicios, talleres, oratorios, etc.). Esto, en principio va a tener respuestas distintas según sea la tradición académico disciplinaria (J.J. Brunner ${ }^{1}$, 1985) y el contexto cultural en que se inscriban. En este mismo sentido, y atendiendo a las tradiciones más relevantes que se pueden reconocer en el campo pedagógico, según Rojas (2006), se pueden identificar al menos tres que serían las siguientes:

a) la tradición alemana representada por Diltbey y Herbart y el enlace entre la pedagogía, la filosofía y las bumanidades; b) la tradición anglosajona

I Según Brunner "una tradición intelectual asumida por un grupo de individuos que tienen en común, además de unos conceptos, unas técnicas y procedimientos explicativos, unos problemas teóricos y sus aplicaciones empíricas" (1985, p. 32). 
representada por Dewey y el enlace con la sociología funcionalista y la psicología experimental en la denominación de ciencia de la educación, y c) la tradición francesa representada por Durkbeim, Debesee y Mialaret y su referencia a las ciencias de la educación (p. 26, nota II).

Es decir, el significado en uso de los dos conceptos basales que nos ocupan aquí (Pedagogía y Educación) ha dependido, en último término, de las corrientes de pensamiento pedagógico que más han gravitado en el medio y finalmente en las tradiciones académicodisciplinarias a las que se han adscrito sus cultores (De Tezanos, 2007).

El período que nos ocupa el siglo XIX constituye un marco histórico de referencia fundamental para el momento de construcción científica de la Pedagogía como saber disciplinar, es un momento relevante para el desarrollo de la especificidad de la Pedagogía como saber científico. Como sostiene un autor:

En el ámbito general de bistoria de las ideas que involucra al pensamiento educativo y pedagógico, una etapa nueva está representada por pensadores que dan a la pedagogía un carácter sistemático $y$, por ende, van legitimando y fundamentando para ella el carácter de ciencia o saber autónomo (Saavedra, 2005, p. 12).

Esta problemática de "cientificidad" de la pedagogía transita histórica y culturalmente por un proceso de constitución epistemológica germinal, por la construcción de su propio estatuto epistemológico. Tal como lo afirma Bowen (1992),

a lo largo de todo el siglo XIX la expresión ciencia de la educación apareció cada vez con mayor frecuencia, $y$ los educadores se preocuparon por el intento de bacer que la educación fuese cientifica y por tanto predecible (p. 4I8).

Durante este período diversos filósofos y teóricos de la educación problematizan la cuestión educativa, problematizan el discurso pedagógico según los saberes teóricos, científicos y filosóficos vigentes en su tiempo. Se trata de un momento de elaboración epistemológica, 
de una experiencia "mayéutica" en la construcción de una nueva ciencia, del nacimiento de la pedagogía como ciencia autónoma, independiente y con validez general.

Si bien los antecedentes más remotos en torno a esta fase en la evolución del pensamiento educativo tiene sus orígenes durante el siglo XVII en la obra de Juan Amos COMENIO (considerado por ello como el fundador de la Pedagogía moderna), este proceso se prolonga y madura lo largo del siglo XVIII "el siglo pedagógico por excelencia” (Luzuriaga, 1973) y comienzos del XIX (PESTALOZZI, por ejemplo), hasta alcanzar un primer estadio de organización formal seudocientífico como saber sistemático, como pedagogía, gracias al aporte de innumerables educadores, entre los que sobresale Johann Friedrich HERBART, quien representa el nuevo espíritu científico aplicado a la educación. Al respecto Dilthey ${ }^{2}$ (1984), al referirse a los orígenes de la Pedagogía como saber sistemático, señala a diversos autores que se ocuparon de esta problemática y contribuyeron a su desarrollo y profundización. Entre ellos destaca a los siguientes: a) Ernesto Cristian TRAPP, quien publica en I780, "Ensayo de una Pedagogía"; b) Immanuel KANT, que publica en I783, "Tratado de Pedagogía"; c) H. NIEMEYER, quien publica en I799, "Principios de educación e instrucción"; d) J. F. HERBART, quien en 1806 publica "Pedagogía general deducida del fin de la educación”; e) F.H.C SCHWARZ, teólogo, profesor en la Universidad de Heidelberg y reformador educativo que tuvo cercanía con Pestalozzi. Además de dirigir durante muchos años el Pëdagogische Seminar, Schwarz escribió dos obras importantes sobre educación: "Erziebungslebre" (tres volúmenes entre 1802 y I813) y "Lebrbuch der Pädagogik und Didaktik”, traducida al castellano, en I846, como "Pedagogía - Tratado completo de Educación y Enseñanza". A los aportes anteriores hay que sumar, indiscutiblemente, los realizados por el propio DILTHEY, quien se ocupó en distintos momentos (entre I874-I894) del tema en particular, cuestión que ocupa, por lo demás un lugar importante en su producción intelectual. En I884 publicó el tratado "Sobre la posibilidad de una ciencia pedagógica con validez general".

2 Wilhem Dilthey (I833-I9II) filósofo alemán que ejerció una influencia significativa en el pensamiento pedagógico contemporánea, particularmente en el ámbito epistemológico. 
No obstante, y a pesar de todos los esfuerzos señalados y los que se han dado posteriormente por consolidar epistemológicamente este saber, por establecer con claridad la cuestión referida a la apropiación del sentido y significado asignado y reconocido tanto al concepto de educación como al de pedagogía (Mialaret, I96I; Braido et al., I962; Fullat, I99I) aún hoy el tema no está resuelto del todo, es decir no está zanjado y esclarecido definitivamente, lo que es una clara y evidente señal del estado actual por el que atraviesa la Pedagogía como saber científico: Para unos, la educación designa tanto el hecho en sí, el fenómeno, como la reflexión o la ciencia que lo estudia; en otros ambientes el vocablo "pedagogía" (pedagogy) es sencillamente desconocido o bien suplido muchas veces por el de educación (education) como sucede en la tradición anglosajona, por ejemplo. Para los franceses, con Durkheim a la cabeza, el concepto de pedagogía en minúscula significa una cosa muy distinta, en este caso: capacidad que el profesor tiene para enseñar, vale decir, arte de enseñar (De Tezanos, 2006). Gastón Mialaret, por su parte, en Les sciences de l'education (I976), reconociendo en este campo (Bourdieu) el gran desorden que reina en la terminología en uso - situación que aporta confusiones numerosas y complejas, propone, por su parte, sustituir el vocablo pedagogía por el de ciencias de la educación... Es decir, esta situación de indefinición y ambigüedad conceptual, de falta de precisión, de claridad semántica y de coherencia semántica que afecta aún el vocabulario educacional, nos da cuenta no solo de uno de los obstáculos epistemológicos más descollantes que ha manifestado en su desarrollo disciplinar específico, sino además de su actual status epistemológico, de su condición de cientificidad aún precaria, que la muestra como un proyecto científico en construcción (Fullat, I998; Flórez Ochoa, 2000).

Si aún al presente la Pedagogía no es una ciencia plenamente autoconstituida, no es una disciplina del todo unificada, ni suficientemente diferenciada de las demás ciencias sociales, como afirma Rafael Flórez Ochoa (2000), con tanto mayor razón la tarea se torna ardua al momento de tratar de conocer y comprender el panorama de base que caracteriza y condiciona la comprensión 
del origen y significado pleno de la propuesta de Don Bosco hacia mediados del siglo XIX. A fortiori, si a ello le agregamos la complejidad que trae consigo la estrecha relación que se establece entre educación, sociedad y cultura, relación en la cual la educación se muestra particularmente vulnerable. Es decir, el discurso educativo/ pedagógico especialmente en su proceso de socialización se hace fácilmente permeable por los contenidos ideológicos y políticos vigentes en el contexto histórico, cultural y geográfico determinado (Flórez Ochoa, 2005; Gvirtz y Palamidessi, 2002; Pérez Gómez, 2002; Hargreaves, 1996; Bourdieu, 1990). Todo ello no es ni puede ser indiferente a la propia acción educativa, a los procesos de enseñar y de aprender, a la acción didáctica. Es más, no es ni puede ser indiferente por cuanto en ella no solo subyacen modelos didácticos sino además modelos curriculares que establecen modos y criterios de selección y legitimación de contenidos, así como Modelos teóricos, conceptuales, categorías epistemológicas en los que se funda y se sustenta.

La problemática de base plantea, por lo tanto, un alto nivel de complejidad. ¿Qué revisaremos en cuestión: la historia de la escuela, la historia de los métodos de enseñanza, la historia de la escolarización en tiempo de Don Bosco, la historia de la profesión docente? Ciertamente que esto tiene un tremendo valor y significado y guarda una relación estrechísima con nuestros objetivos de estudio. En la propuesta de Don Bosco, sin lugar a dudas que se han de encontrar elementos, criterios, líneas directas o indirectas, explícitas y/o implícitas que apunten en estas direcciones, bien que puedan inferirse sin mayor mediación de sus propias apreciaciones, dichos, experiencias recogidas por sus más cercanos, escritos formales e informales y enseñanzas acrisoladas en la práctica educativa que le cupo desarrollar. Como se puede observar se nos abre un abanico de posibilidades de proporciones insospechadas, lo que nos obliga, sin duda, a tener que acotar, a delimitar necesariamente nuestro campo de indagación. Como decían los antiguos: "Ars longa, vita brevis" (El arte es inmenso y la vida es corta). 
Pero, en fin, conscientes de que la pedagogía es una disciplina que ha discurrido por diferente carriles sin alcanzar una clara demarcación científica, que es aún un saber insuficientemente sistematizado, y sin pretender resolver estas complejidades pero con el propósito de poder avanzar en nuestras indagaciones en relación a los significados asignados a los conceptos de Pedagogía y Educación (Braido, I962; Mialaret, I97I; Fullat, I99I) que están a la base de nuestros propósitos indagativos, tomaremos provisionalmente una posición o perspectiva al respecto, posición que nos parece más razonable y que se encuentra comúnmente aceptada en nuestro medio:

Con el concepto PEDAGOGÍA (Pädagogik) se busca designar el ámbito de reflexión y teorización de la educación. Es el mundo de las ideas (pedagógicas). La Pedagogía según Dilthey (I968), se define como "teoría de la formación" (De Tezanos, 2006), de tal manera que este saber pasa a ser una disciplina, y por eso le compete la teoría. Es decir, la Pedagogía mirada desde esta tradición cultural, académico disciplinar, se constituye en ciencia. La ciencia de la educación.

Con el concepto EDUCACIÓN (Herziebung), a su vez, se hace referencia a la dimensión práctica, al quehacer, a la acción educativa. Es el mundo de la realidad (educativa). La educación es un tipo de saber (sapientbia - sopbia), un tipo de saber que no pertenece, en sentido estricto, al saber teórico, especulativo, es más bien un tipo de saber práctico, una ciencia práctica, un conocimiento de y para la acción, en y desde la acción (Altarejos, 1998). Desde esta perspectiva la educación se sitúa por lo tanto en el ámbito de la acción, en el ámbito del saber práctico y no teórico, ámbito al interior del cual es preciso distinguir una vez más entre el saber práctico relacionado con un bacer (facere, factibilia, orientado a la producción de un objeto útil) y el saber práctico relacionado con un obrar (agibile, agibilia, orientado a la acción bumana moralmente recta) según el acertado principio de distinción aportado por la tradición aristotélico tomista que nos permitimos aplicar aquí (Maritain, I958; 1955; Altarejos, 1998).

La educación, por tanto, pasa a constituirse así en el objeto de estudio de la Pedagogía como saber disciplinar. En conclusión, la Pedagogía, 
en tanto reflexión sistemática sobre la educación, viene a constituirse en la ciencia de la educación, en el saber; la Educación, en cambio, en tanto acción educativa, es un arte, un arte particularmente difícil, es el arte del saber práctico, del saber hacer dimensión fáctica, y saber obrar dimensión axiológica (Fullat, I99I), lo que la hace ser, finalmente, más que un mero arte técnico, un arte esencialmente moral (Maritain, I98I).

No obstante, ante esta aparente dicotomía u oposición que pudiere inferirse de manera primaria uno constata una clara distinción entre dos realidades que terminan siendo desde el punto de vista del conocimiento complementarias, al punto que podemos reconocer que: "la educación y la pedagogía están en la relación de la práctica y la teoría, de la realidad y la idealidad, de la experiencia y el pensamiento, pero no como entidades independientes sino fundidas en una unidad indivisible, como el anverso y el reverso de una moneda." (Luzuriaga, 1973, p. I2). La distinción epistemológica que se deba establecer no está planteada para separar u oponer sino para unir. "Si la educación y la pedagogía representan, respectivamente, el aspecto práctico y teórico de un mismo proceso dinámico bumano afirma Mialaret, ban de ser, por lo mismo, inseparables" (I96I, p. I6).

¿Cuál es la tradición que se impone en ese contexto?, ¿por dónde camina Don Bosco, por dónde transitan sus miradas, sus experiencias, sus reflexiones? No resulta fácil poder resolverlo. Ya sabemos con antelación que no elaboró ningún tratado sistemático de Pedagogía y/o de Educación. El mismo maestro de Valdocco en uno de sus escritos señala:

Muchas veces se me ba pedido exponga, de palabra o por escrito, algunos pensamientos sobre el llamado sistema preventivo, practicado en nuestras casas. Por falta de tiempo - subraya Don Bosco no be podido basta abora satisfacer tales deseos; mas disponiéndome en la actualidad a imprimir el Reglamento usado ordinariamente hasta el presente casi por tradición, estimo oportuno dar aquí una idea que será como el índice de una obrita que estoy preparando y que publicaré, si Dios me da vida y salud para terminarla. Hago esto movido únicamente por el deseo de aportar mi granito de arena al difícil arte de educar a la juventud. Diré, pues, en qué consiste el sistema 
preventivo y por qué debe preferirse; sus aplicaciones prácticas y sus ventajas (El sistema preventivo en la educación de la juventud. : 56I566. MB I3, 918 - 923).

Don Bosco si bien no tuvo ni el tiempo ni la ocasión y así lo expresa en el texto tuvo al menos el deseo, la disposición, la intención de escribir y sistematizar sus ideas en torno a la educación, pero siempre entendiendo que sus "ideas", sus reflexiones, serían la sistematización de un modo de enseñar ("llamado sistema preventivo, practicado en nuestras casas"). Ellas no tendrían por finalidad abordar principios ontológicos, abstractos y especulativos, principios primeros sobre la educación; estarían, por el contario, orientadas a guiar la acción educativa. Il amico della giovennezza no quiere especular, no quiere teorizar sobre el tema, esos no son sus propósitos, aquello no está en el horizonte de sus preocupaciones, lo que él quiere es aportar al arte (“... al difícil arte...” ) de educar a los jóvenes, esa es su primera preocupación. Don Bosco es esencialmente un hombre de acción.

Por lo demás son tiempos, los suyos, en que aún se escribe en torno a la educación de manera fundamentalmente ensayística, retórica, discursiva, en algunos casos algo más "vivencial", autobiográfica y en algunos de modo puramente intuitivo y, por qué no decirlo, hasta poético, en otros. Su afirmación de que "La educación es cosa del corazón", es sumamente ilustrativa al respecto.

\section{Componentes socio/culturales e histórico/ contextuales de la Europa del siglo XIX:}

\section{Principales teóricos de la Pedagogía en tiempos de Don Bosco:}

Establecidas, entonces, estas primeras distinciones de carácter conceptual y epistemológico que hemos subrayado someramente, nos aproximaremos ahora a algunos de los teóricos de la Pedagogía más representativos e influyentes en la Europa del siglo XIX particularmente italianos, para intentar conocer y comprender el 
contexto educativo y pedagógico en el cual Don Bosco va elaborando su propuesta educativa. Queremos indagar en alguno de ellos, a través de sus planteamientos más centrales, las posibles influencias, conexiones y cercanías con la propuesta educativa de Don Bosco, apreciar posibles huellas y vestigios procedentes de otras experiencias educativas que él recoge y hace suyas.

Entre los grandes teóricos y principales educadores que es preciso reconocer porque sobresalen en el contexto pedagógico del siglo XIX (Suizos y alemanes particularmente), cabe destacar en primer lugar a Jean Jacques ROUSSEAU (I7I2-I778), padre del naturalismo pedagógico, quien seguirá ejerciendo una influencia extraordinaria que se prolonga hasta el presente. Sin lugar a dudas que no podemos dejar de nombrar aquí algunas otras figuras señeras que marcaron época en este campo como son: Immanuel KANT (I724-I804); Johann Enrich PESTALOZZI (I746-I827); Albertine Necker DE LA SAUSSURE (I766-I84I); Johann Friedrich HERBART (I776 -I84I) y Friedrich FRÖEBEL (I782-I852).

Ahora bien, entre los pedagogos italianos que ofrecen una mayor cercanía, tanto geográfica como cronológica, con respecto a nuestro autor, podemos destacar a: GIOGIA, Melchiore (I767-I829); CUOCO, Vincenzo (1770-I823); ROMAGNOSI, Doménico (I76II835); GALLUPI, Pascuale (I770-I846); ROSMINI, Antonio (I797-I855); GIOBERTI, Vincenzo (I80I-I852); MAZZINI, Giuseppe (I805-I872).

En nuestro afán por identificar a los pedagogos italianos más connotados y contemporáneos a Don Bosco, hay que reconocer y destacar a su vez los movimientos y corrientes ideológico políticas predominantes en torno a las cuales se agrupan o alinean estos personajes (Abbagnano y Visalbergi, 2005): Por ejemplo entre los pedagogos representantes del catolicismo liberal encontramos a: LAMBRUSCHINI, Raffaele (I788-I873); APORTI, Ferrante (I79I-I858); CAPPONI, Gino (I792-I876); SACCHI, Giuseppe (I804-I89I). Entre los Pedagogos positivistas: CATTANEO, Carlo (I80I-I869); FERRARI, Giuseppe (I8I2-I876). 
Entre los autores que reconoce y subraya el propio Don Bosco en sus MEMORIAS DEL ORATORIO (MO, 200I), con quienes además tuvo algún grado de contacto y cercanía se pueden identificar las siguientes figuras:

a).- Al abate Ferrante APORTI (I79I-I858), célebre figura del catolicismo liberal y pedagogo de renombre que llegará a ser Rector de la Universidad de Turín. Don Bosco lo señala como uno de los profesores que asisten (en el año I846) a una demostración pública que ofrece en torno a los aprendizajes logrados por sus alumnos en las clases de la Escuelas dominicales y nocturnas que él atendía y asistía con algunos colaboradores (MO, 200I, pp. 205-210). Además, según algunas indicaciones que señala Peraza (tanto en su edición crítica de las Memorias del Oratorio la nota 203, al pie de página como en otros estudios), Don Bosco habría sido oyente de los cursos sobre metodología para la enseñanza que impartió el abate Aporti entre los meses de agosto a octubre de I844 (MO, 200I, p. 208; Peraza, 2003, p. I26). Aporti, según Braido (I993),"no sólo concepisce l'educazione como prevencione, ma adotta esplicitamente la prevenzione nell'educazione" (p. 84).

b) José RAYNERI (I809-I867) este prestigioso pedagogo turinés y profesor del Ateneo de Turín, es el segundo profesor asistente a la demostración pública de aprendizajes logrados por los alumnos a los que se refiere Don Bosco en sus Memorias del Oratorio (200I). Sobre esto no dice más al respecto.

c) Antonio ROSMINI SERBATI (I797-I855). Sacerdote, filósofo y pedagogo nacido en Rovereto, fue además, fundador del "Instituto de la Caridad", Congregación religiosa nacida en I828 y conocida comúnmente como los rosminianos o padres de la caridad. A juicio de algunos autores (Simoncelli, 1967; Perelló,1995), Rosmini ha sido considerado como un intelectual brillante y uno de los mayores teóricos católicos de la Pedagogía del siglo XIX. Está señalado por el propio Don Bosco en sus Memorias como uno de aquellos sacerdotes que le prestaron provisionales ayudas en el Oratorio en momentos de grandes dificultades (MO,200I, pp. 235 - 237). 
¿De qué manera y cuánto influyeron estos pedagogos en el ideario donboscano?, ¿Cuáles pudieron ser los ideales que, de cada uno de ellos, Don Bosco hizo suyos? En este afán por adentrarnos progresivamente en la propuesta educativa del Maestro de Valdocco, revisaremos, siguiendo básicamente las pistas que nos ofrece Braido (1993), la lista de aquellos "educadores" que abordan y contribuyen a la elaboración del concepto de Preventividad como fórmula pedagógica que Don Bosco hará suya, otorgándole un sello propio y singular. Aun cuando estimamos que el autor lleva demasiado lejos la búsqueda de los orígenes de la tradición de la preventividad, no obstante los antecedentes aportados, especialmente para el siglo decimonónico, son particularmente interesantes. Entre los autores más estrechamente relacionados con el nacimiento y el cultivo del "sistema preventivo" en el ámbito educativo Braido destaca a: Antonio Angelo (I772I858) y Marco Antonio (1774-I853) CAVANIS; Ludovico PAVONI (I784-I849); Marcelino CHAMPAGNAT (I789-I840); APORTI, Ferrante (I79I-I858); Pierre Sébastien LAURENTIE (I793-I876); ROSMINI, Antonio (I797-I855); Teresa Eustochio VERZERI (I80I-I852); Pierre - Antoine POULLET (I8I0-I846); Felix DOPANLOUP (I802-I878).

Podemos apreciar, por un lado que Don Bosco no solo conoció a connotados pedagogos de su tiempo, sino que además tuvo contactos con algunos de ellos. Del mismo modo sabemos que conoció de cerca las experiencias educativas de los Hermanos de las Escuelas Cristianas, así como la experiencia educativa de los Barnabitas y de los Escolapios. Por otra parte podemos apreciar también que el término preventividad y el tema mismo en cuestión no son ajenos al discurso pedagógico ni a la praxis educativa de su tiempo, sino además estaban arraigados en la más genuina tradición educativa católica desde tiempos remotos (Braido, 1993), tradición educativa que Don Bosco sabrá recoger y expresar con lucidez y acierto en una síntesis nueva a partir de la cual se verá surgir la fórmula pedagógica salesiana del sistema preventivo en cuestión. 


\section{Aproximaciones al pensamiento educativo de Pestalozzi}

En el siguiente punto quisiéramos abordar algunas de las ideas educativas de Pestalozzi, educador de gran renombre y prestigio, un hombre de tradición protestante y de gran sensibilidad social, por cuanto sus ideas repercutieron de una manera extraordinaria en la educación y la pedagogía moderna y representa una de las figuras más brillantes del siglo XIX (Bowen, 1992). De Pestalozzi no solo se ha dicho que ha sido "el genio mayor, la figura más noble de la educación y de la pedagogía, el educador por excelencia...” (Luzuriaga, I973, p.I75), sino también, como afirma Meylan, que "de todos los educadores y filósofos de la educación, Pestalozzi es probablemente el único conocido en los cinco continentes, el único que ba llegado a la grandeza mítica de un Beetboven: el genio pedagógico"(Chateau, 1974, p. 203).

Entre sus principales obras encontramos "Las veladas de un ermitaño" (I780), "Leonardo y Gertrudis" (I78I), "Cómo Gertrudis enseña a sus bijos" (I80I) y "El canto del Cisne" (I827). A partir de aquí podemos subrayar las siguientes ideas:

I. Pestalozzi, al igual que Jean Jacques Rousseau, de quien se reconoce discípulo, no expuso sus ideas pedagógicas de una manera sistemática. Se diría más bien que están dispersas materialmente en sus distintas obras, pero que sin embargo, en su conjunto ofrecen una cierta unidad orgánica.

2. Como un buen exponente del romanticismo predominante en el siglo XIX, Pestalozzi funda su idea de la educación en la naturaleza, haciendo suyos los planteamientos rousseaunianos del nuevo espíritu de la filosofía de la naturaleza.

3. Sostiene que la educación, para respetar la naturaleza humana, debe seguir el camino que ha tenido que recorrer la propia humanidad: pasar desde el estadio animal, del ser instintivo, hasta alcanzar el estadio de desarrollo social y moral.

4. Destacan en ella su profundo espíritu humanitario y filantrópico. 
5. Buscó siempre ofrecer una educación de fuerte sentido social, que pudiera mejorar la situación de las clases más pobres y humildes. En Pestalozzi se ve al creador e impulsor de la escuela popular.

6. La familia juega un rol central en el pensamiento pestalozziano. No es sólo la escuela la que importa. "La familia es para él señala Luzuriaga el núcleo primordial del cual surgen las demás instituciones sociales” (1973, p. 177). Aquí está no solo el punto de arranque, sino además la base de toda educación. Al respecto Pestalozzi sostiene: "Casa paterna, eres la escuela de las costumbres y del Estado. Por eso eres, bogar paterno, el fundamento de toda educación natural de la bumanidad ” (Las veladas de un ermitaño; Luzuriaga, 1973, p. 178).

7. Respecto de la finalidad de la educación, para Pestalozzi es la humanización del hombre. Al respecto señala: "La educación verdadera y natural, conduce bacia la perfección, bacia la plenitud de las capacidades bumanas". Es preciso recordar en este contexto la presencia e influencia de Basedow y su ideal filantrópico pedagógico (cuya experiencia y principios plasma en la escuela "Philanthropinum", en I774), que tiene sus raíces en Rousseau, y que ejerce, además, una gran influencia en el medio racionalista e ilustrado, en figuras como Trapp y Campe.

8. Al hacer referencia a las capacidades humanas que la educación debe desarrollar en el niño para conducirlo hacia su plenitud afirma: "Es una verdad universal que solo es esencial y realmente educativo to que afecta a los bombres en el conjunto de sus capacidades, esto es, del corazón, el espíritu y la mano". Aquí el pedagogo subraya una distinción fundamental de las capacidades del ser humano que han de procurar ser cultivadas: la vida intelectual (el espíritu), la vida moral (corazón), y la vida práctica (las manos), a la que debe avocarse la tarea educativa. Promover la vida toda, en forma global. "Todo lo que no afecta a la totalidad de su ser no le afecta naturalmente y no es bumanamente educativo en toda la extensión de la palabra".

9. Desde el punto de vista antropológico Pestalozzi sostiene que el hombre es un ser instintivo o animal, pero también un ser social y moral. Por lo tanto sostiene que a cada una de estas características 
se asocia no solo un estadio o etapa de su desarrollo, sino que además a ello correspondería un tipo particular de educación, de tal manera que al primer estadio del desarrollo humano está asociada la familia, y por ende la educación familiar; al segundo, el Estado, y la educación escolar; y finalmente, al tercer grado de desarrollo está asociada la humanidad, a la que correspondería la educación social y moral.

I0. Sostuvo también la idea de una escuela como comunidad, es decir la idea de una escuela que, siendo esencialmente educativa, permitiera la vida en común de maestros y alumnos, con una finalidad social.

II. La escuela para Pestalozzi tiene un carácter no sólo social, sino además un carácter activo, práctico, laborioso, de actividad tanto manual como intelectual, pero ambas a la vez, unidas y permanentes. He aquí un principio de la Escuela Activa de la cual el propio Rousseau es uno de los precursores. Es decir, los niños deben aprender trabajando, aprender baciendo (learning by doing, como sostendrá más tarde John Dewey). "Los conocimientos sin las actividades prácticas sostiene el Pedagogo Suizo/alemán constituyen el don más funesto que un genio enemigo ba becho a nuestra época". Es el principio de "aprender por la propia experiencia", principio que había sostenido la pedagogía de Rousseau.

I2. Pestalozzi sostuvo que la educación debía ser profundamente realista, no abstracta, ni irreal, o descontextualizada del ámbito social en que viven los niños. Ella debe partir de las circunstancias reales e inmediatas en que se encuentran los educandos.

13. La educación debe partir con una formación general, educación elemental, para poder guiarlos hasta el descubrimiento de su vocación propia y singular, que les permita alcanzar una formación profesional.

I4. Pestalozzi reconoce el valor de la educación ético religiosa, sensus lato, naturalista, aunque a su juicio esta última no se adquiere por medio del arte de enseñar. "La vida educa", es el principio único y fundamental que se desprende de su obra tan temprana como Las veladas de un ermitaño y El Canto del cisne. 
I5. Su pedagogía, heredera de la pedagogía de Juan Jacobo Rousseau, se encuentra caracterizada entre las corrientes idealista, filantrópica, naturalista.

I6. Se podría afirmar que la pedagogía de Pestalozzi valora y exige la acción (del educando) y rechaza el verbalismo excesivo (del educador). Aquí una vez más la línea de trabajo educativo que es heredera, en parte, de las propuestas de Basedow puestas en acción en el Pbilantbropinum y de algunas otras experiencias tanto en Suiza como en Alemania. El maestro de Yverdon centra la actividad educativa en el niño. "El niño, como el bombre, quiere el bien, mas no para ti, educador, sino paraél mismo. El bien a donde debes conducirlo no debe ser tu capricho, una sugerencia de tu pasión, sino que debe ser un bien por sí mismo y aparecer como tal bien al niño... Todo aquello que despierta en él fuerzas, que le bace decir; yo puedo, él lo quiere. Pero este querer no se suscita con palabras, sino con los cuidados que se le prodigan y con las fuerzas que esos cuidados despiertan y estimulan en él" (Abbagnano y Visalbergi, 2005, p. 470). Es la educación paidocentrica de la Escuela Nueva.

\section{Algunas reflexiones a modo de conclusiones}

En definitiva, y luego de este breve recorrido por el contexto pedagógico del siglo XIX en el que vivió Don Bosco, nos parece oportuno poder establecer $y$ apreciar algunas aseveraciones en torno a su vida, a su figura, a su estilo, a su propuesta educativa... que lo identifican, lo caracterizan y lo distinguen en medio de los demás educadores. Algunas de estas son las siguientes:

I. Es indudable que Don Bosco no fue ajeno a la influencias educativas y pedagógicas que gravitaban en su tiempo, por lo tanto nos parece que muchas de sus ideas que están en el marco de su sistema preventivo, si bien van adquiriendo matices distintos a partir de su propio estilo, son cercanas, familiares y hasta populares en el medio en el que a él le tocó vivir. Muchas de estas ideas y prácticas educativas se encuentran ya formuladas en los autores más influyentes de la Europa decimonónica (La Salle, Necker de Saussure, Lambruschini, Rosmini, y particularmente 
como las planteadas por Pestalozzi), como se ha podido apreciar.

2. El maestro de Valdocco, sin embargo, es ajeno a las corrientes academicista, cientificista y positivista del siglo XIX. Don Bosco no entra en esos movimientos que buscan desarrollar la "ciencia de la educación" como es la situación de los educadores en Francia, Italia y Alemania. Es decir, no se asocia a la construcción de esta "nueva disciplina" en la efervescente sociedad del siglo XIX en medio de la cual surgían las ciencias sociales, con el complejo de las ciencias naturales.

3. Don Bosco es un hombre ajeno al ámbito académico, no escribe tratados sistemáticos de Educación y/o Pedagogía para el mundo de la academia, para los teóricos, para el mundo universitario; él no participa de los grandes debates intelectuales de su tiempo en materias teórico especulativas sobre los temas que aquí nos ocupan. No hay en él un afán de establecer una suerte de SUMMA PAEDAGOGICA desde una perspectiva especulativa, de elaborar una obra de síntesis al modo como la presenta un Santo Tomás de Aquino, en Teología, en el siglo XIII, por ejemplo. Don Bosco es más bien un hombre que vive la experiencia educativa, la experiencia formativa, la práctica docente de una manera muy consciente y vívida. Su propuesta es "experiencial”, esencialmente "experiencia educativa", síntesis vital y práctica de quien era "evidentemente un hombre de acción" como lo sostienen diversos especialistas (Braido, Peraza, Prellezo, Stella, Nanni).

4. Sus escritos sobre educación son obras de circunstancias, por consiguiente son escritos que reflejan su sentir y su pensar a lo largo de distintos momentos de su vida. Además, no solo se hallan dispersos en el conjunto de sus numerosos escritos, sino que son de factura diversa: algunos de ellos han sido escritos y reescritos de su puño y letra, otros han sido redactados por terceros pero dictados por Don Bosco, otros son versiones abreviadas de sus textos y finalmente hay alguno que según la crítica sólo son escritos inspirados en el Santo. (Peraza, 2003). Sin embargo y a pesar de la dispersión "material" del corpus -, se puede apreciar en ellos una cierta unidad "formal", un orden, 
una estructura lógica del pensamiento pedagógico donboscano lo que nos permite afirmar que hay ahí un conjunto de elementos y componentes teórico-conceptuales y prácticos (principios, fines, medios y métodos) a partir de los cuales es posible apreciar un Modelo pedagógico, un Sistema educativo. San Juan Bosco crea un "Sistema". Por lo demás, ¿puede haber una "acción educativa" que no contemple una concepción teórica de base, una visión teórica fundante?

5. A pesar del marcado acento práctico de su propuesta educativa, Don Bosco esboza a grandes rasgos, traza una teoría, es decir, un "discurso" explícito, una reflexión organizada sobre la educación. Ciertamente no se podrá reconocer en él ni un vocabulario normalizado, ni un tratamiento académico, universitario, formal; tampoco encontraremos anotaciones de orden metodológico sobre el procedimiento a seguir ni consideraciones epistemológicas sobre la validez del conocimiento adquirido, como sostiene particularmente Guy Avanzini (Prellezo, 1990)

6. Los sujetos preferentes de la acción educativa de Don Bosco son los jóvenes, especialmente los más pobres, analfabetos, huérfanos, aquellos que experimentan y sufren los efectos de la miseria, del riesgo social, de la orfandad y la marginación. La propuesta educativa donboscana se sitúa, por tanto, en la vertiente de la educación popular.

7. Su labor educativa, sin embargo sin dejar de preocuparse por las condiciones sociales deprivadas de ellos, de sus necesidades y carencias tanto materiales como afectivas, va más allá de la mera filantropía o del simple espíritu humanitario tan común y propio de la sensibilidad cultural europea del siglo XIX. Su acción educativa, su visión cristiana de la educación está sostenida y movilizada por una exigencia evangélica, por un claro sentido escatológico; su ideario tiene un sentido (o carácter) espiritual, sobrenatural, trascendente. Su mirada sobre "la pobreza", su compromiso con los pobres no es puramente social, no es una acción simplemente liberadora, ella es esencialmente evangélica, salvifica: "Da mibi animas coetera tolle" (Denme almas y llévense lo demás), sentencia el amicco della giovennezza. Sus propósitos educativos no 
son puramente humanitarios, sociales, técnicos, intelectuales o artísticos sino también y sobre todo, diremos evangelizadores.

8. El fin de la acción educativa no es la mera humanización del sujeto educando; la acción educativa no apunta solo a brindarle algún tipo de ayuda filantrópica a los jóvenes, a ofrecerles conocimientos o dominios técnicos sobre un arte o actividad, a procurar el desarrollo de habilidades y competencias instrumentales que les permita alcanzar el dominio de un oficio y procurar así su bienestar social y material. Por el contrario, se puede apreciar que hay en ella, esencialmente y sobre todo, un claro sentido trascendente, una preocupación profunda por la dimensión espiritual, moral y religiosa del hombre: "Se les proporcionará alojamiento, comida y ropa; y a la vez que se instruyen en las verdades de la fe católica, serán también encaminados bacia algún arte u oficio", señala Don Bosco en las Constituciones (Constituzioni, I875: I, 4). Como dirá Cassotti (Braido, I993), "Il sistema di D. Bosco è un sistema di educazione e di pedagogía integrale cioè non solo naturale, bensi anche sopranaturale" (p. 100). Podemos afirmar que Don Bosco centra su mirada en el "núcleo principal de la persona"; al amigo de la juventud le interesa la salvación del joven; su camino educativo se orienta centralmente hacia la persona como realidad; la santidad, como expresión suprema de la plenitud de vida, que no es posible sin una referencia absoluta a Dios, es la propuesta entusiasta que le ofrece a los jóvenes. "Formar buenos cristianos y bonestos ciudadanos", procurar la promoción humana integral, constituyen en último término las metas de su afán educativo. La educación debe conducir hacia la santidad de vida.

9. Don Bosco vive la experiencia educativa originaria y fundante de Valdocco como lo hace también, el mismo Pestalozzi en Neuhof, en Stans, en Berthoud y en Yverdon, por ejemplo, explorando y reflexionando desde la acción educativa cotidiana, desde sus singulares espacios educativos como son las prácticas "oratorianas", experiencias educativas, respuestas educativo/pastorales nuevas que sean capaces de hacer frente a las necesidades de los jóvenes, experiencias todas (aciertos y desaciertos, éxitos y fracasos) que va plasmando en los diversos 
Reglamentos (reglamentos de las compañías y asociaciones piadosas que se fueron fundando en el Oratorio y en los colegios), especialmente en el denominado Reglamento de las casas, y que recoge también y sobre todo en sus Memorias y escritos diversos, movido fundamentalmente ("únicamente") por el deseo de "aportar como subraya él mismo "mi granito de arena al difícil arte de educar a la juventud” (MB I3, 9I8 - 923). Mención aparte merece la "Carta de Roma", del I0 de mayo de I884, considerada como carta maestra de su narrativa pedagógica (Peraza, 2003). Es decir, Don Bosco reconoce y valora la acción educativa, reconoce y valora la "sapienza" educativa que se hace "saber pedagógico". La propuesta donboscana es primordialmente EDUCATIVA más que PEDAGÓGICA.

IO. Don Bosco no persigue como afán, creciente entonces en los "pedagogos", elaborar un método intrínsecamente bueno, es decir, una didáctica válida por sí misma y cuya eficacia sería independiente de la calidad relacional de los que la utilizan, es decir, una pura y simple herramienta, un mero instrumento, pura racionalidad técnica, instrumental, a ser aplicada (Avanzini,I990). "Tal vez diga alguno que es difícil este sistema en la práctica, sostiene Don Bosco; a lo que respondo -continúa- que para los alumnos es bastante más fácil, agradable y ventajoso" (MB, 13). Advierte, sin embargo, que si bien es cierto a los educadores les puede ofrecer algunas dificultades, estas se verán significativamente disminuidas en la medida en que se entreguen por entero a su misión, al fin que se proponen que es la educación moral, intelectual y ciudadana de sus alumno. "El educador - afirma Don Bosco- es una persona consagrada al bien de sus discípulos, por lo que debe estar pronto a soportar cualquier contratiempo o fatiga con tal de conseguir el fin que se propone" (MB, I3). No es en consecuencia primero y ante todo la eficacia técnica del método, la tèkhne, el saber "bacer", que guía y determina el modus operandi, la acción educativa donboscana, sino el saber "obrar", la rectitud de la acción educativa que exige la intervención de las virtudes morales en la labor educativa del maestro y particularmente el ejercicio de la virtud de la prudencia como virtud normativa y reguladora. Razón, religión y amor, constituyen los pilares en 
los que se funda su propuesta metodológica, en los que descansa este sistema (MB, I3).

II. Así como Don Bosco ve en San Felipe Neri el santo de la alegría, en San Francisco de Sales el santo de la caridad y la dulzura (MO, I I5), en San Vicente de Paul el santo del espíritu de servicio y caridad, encuentra también en San Juan Bautista La Salle algunas grandes iniciativas pedagógicas en torno a la acción preventiva (Braido, 1993), tales como el espíritu religioso y la bondad humana, por ejemplo. De la misma manera se encuentran en Don Bosco referencias a Les douze vertus d'un bon maitre (Hno. Agathón, I880), texto que era de uso común en las prácticas educativas de los Hermanos de las Escuelas Cristianas ${ }^{3}$ y con quienes tendrá más de alguna estrecha colaboración en el ámbito educativo y pastoral (MO, I47; MB, I3).

12. En esta misma perspectiva Don Bosco aborda uno de los problemas centrales de la acción educativa que le abrirá un amplio espacio a su propuesta más emblemática al resolver la dicotomía o antinomia entre preventividad y represión:

"Dos sistemas se ban usado en todos los tiempos para educar a la juventud: el preventivo y el represivo. El represivo consiste en dar a conocer las leyes a los súbditos, y vigilar después para conocer a los transgresores y aplicarles, cuando sea necesario, el correspondiente castigo... Diverso, y casi diré opuesto, es el sistema preventivo. Consiste en dar a conocer las prescripciones y reglamentos de un instituto y vigilar después de manera que los alumnos tengan siempre sobre sí el ojo vigilante del director o de los asistentes, los cuales, como padres amorosos, bablen, sirvan de guía en toda circunstancia, den consejos y corrijan con amabilidad; que es como decir: consiste en poner los niños en la imposibilidad de faltar" (MB I3, 918 - 923).

Es decir, Don Bosco -como sostiene Braido (1993)-, a la luz de la caridad justifica la tensión existente entre vigilancia - presencia y resuelve de este modo el problema del castigo. No cabe la menor duda que Don Bosco - quien conoció el texto Lassaliano de "les douze vertus..."-

3 Quienes, a pesar del enorme prestigio que tenían por ese entonces en Europa, sólo llegan a Turín en I830 llamados por el Rey Carlos Félix para atender a los jóvenes del mundo popular (Peraza, 200I). 
entiende que "la vigilancia de un buen Maestro no ba de ser nunca inquieta ni desconfiada, ni incómoda, ni andar en compañía de conjeturas ayunas de todo racional fundamento" (Hno. Agathón, pp. II0-II2). La antinomia clásica castigo/preventividad encuentra una sólida respuesta en "esa vigilancia (que) ba de ser apacible, sin agitación, ni violencia, ni afectación, ni inquietud: así solo será más perfecta”, como comenta el Hno. Agathón (p. II3)

I3. La proxemia salesiana: Don Bosco valora la relación interpersonal como condición de toda eficacia. El "patio" es un espacio clave, un lugar de encuentro, un espacio privilegiado para conocer a los jóvenes, para compartir con ellos, para formarles, para acompañarles, para prevenir, para animar y animarlos. "Los alumnos no ban de estar nunca solos”, afirmaba el maestro de Valdocco (MB I3, 9I8-923). Él buscaba conocer cada día mejor a los jóvenes, permanecer cercano a los jóvenes. Ellos constituyen su razón de ser, y de actuar. La preventividad como propuesta educativa implica estar abí.

I4. Hay en Don Bosco una síntesis maravillosa de los aportes diversos que vienen de la tradición educativa cristiana en torno a la preventividad. En su propuesta educativa se da una verdadera "confluenza degli elementi tipici della tradizione preventiva" que se encuentran en la secular experiencia educativa católica, así como en las propuestas teóricas difundidas en la cultura de su tiempo, en particular en algunos educadores que le son contemporáneos, como afirma Braido (I993).

I5. Su "sistema" comporta (y exige, por lo tanto) un "estilo" docente, un modo de educar. Su estilo es arte y vida impregnada de vivencia evangélica. Don Bosco es un hombre que vive en medio del mundo (iy qué mundo! La Italia nacionalista, de la unificación, de las ideas liberales, románticas...), pero que tiene su mirada de largo alcance, sin embargo, puesta en la vida espiritual, sobrenatural, en Dios. Él, como educador, como guía, como pastor vive en la presencia de su Señor y vive su presencia, su gracia. Su mirada no es puramente profana. Es una mirada de un hombre de fe, de un hombre de Dios, de un creyente que vive en la alegría de Dios, de saberse llamado (vocare) por Dios a servir a los jóvenes, a vivir en medio de ellos, con ellos, por ellos, y para ellos. Es la mirada y 
la opción de un creyente, es la mirada de un hombre consagrado a Dios que se siente movilizado a entregarse enteramente a los jóvenes. Su fe no solo le sostiene y le mueve, sino que además le amplía su mirada para comprender el sentido trascendente de su acción educativa. Es un educador contemplativo en medio del mundo, es un contemplativo en la acción.

I6. Su "sistema" tiene como referencia paradigmática la vida misma de Don Bosco, es decir, su sistema tiene que ser estudiado en estrecha relación con su vida, con su manera de mirar la vida y los hechos, su manera de encarar los problemas y de resolverlos, de actuar y de relacionarse con los jóvenes, su manera de abordar la acción educativa.

17. Su "ideario" comporta finalmente la idea de un clima propicio, de un "ambiente" comunitario, "familiar" (y en esto concuerda también con Pestalozzi) como medio que facilite y garantice el logro de la acción educativa. El Oratorio, que constituye su primera experiencia educativa, es todo: es ambiente de acogida, lugar de oración, talleres de capacitación, lugar de recreación, espacio de optimismo, de amistad, de alegría... Se presenta como una propuesta educativa integral.

I8 Educación y trabajo. La preocupación educativa de Don Bosco se centró en el esfuerzo por brindarle a los jóvenes más que una mera educación tradicional, clásica, libresca, enciclopédica, ilustrada como era la enseñanza impartida en las escuelas oficiales, pensadas para las élites. Su propuesta educativa se centró en la educación técnica, en el trabajo manual, en una formación que fue evolucionando desde la experiencia de los pequeños talleres de capacitación artesanal hasta las escuelas profesionales. Don Bosco valora la importancia de la instrucción profesional, de la educación técnica profesional porque la ve, además, como una respuesta realista y práctica frente a las necesidades de los jóvenes de su tiempo. En su propuesta se valora el trabajo y podríamos decir que este adquiere todo su valor pedagógico en la propuesta educativa de Don Bosco.

19. Su "sistema" preventivo es paidocéntrico, lo que le aproxima a los postulados de la Escuela Nueva de manera singular. Su pedagogía 
apunta por un sano equilibrio en la relación educador - educando. $\mathrm{Su}$ ideario educativo está lejos del laisse faire del naturalismo rousseauniano y del idealismo pestalozziano, por cierto.

20. En fin, podemos afirmar también -y en esto siguiendo a Perelló (I995)- que, así como Rosmini es el teórico católico de la Pedagogía más brillante del siglo XIX, el Pedagogo, el hombre de la ciencia de la educación, de la teoría, Don Bosco es el mayor Educador, el que sabe hacer, el práctico de la pedagogía, el educador por antonomasia, y uno de los más connotados del siglo.

En síntesis, en Don Bosco se puede encontrar un saber pedagógico fecundo capaz de iluminar los problemas educativos más candentes de nuestro tiempo, y un modelo educativo de particular actualidad que recoge no solo los aspectos más preciados de una larga tradición educativa, sino además se funda en principios y valores permanentes que constituyen los pilares sobre los que se asienta su propuesta educativa, como es el Sistema Preventivo.

\section{Bibliografía}

Abbagnano, N; Visalberghi A(2005). Historia de la Pedagogía. México: Fondo de Cultura Económica.

Agaton, Hno.(1883, I9I7). Las doce virtudes de un buen maestro, según el venerable J.B. de La Salle, institutor de los Hermanos de las Escuelas cristianas, explicadas por..., Barcelona.

Altarejos, F. (1998). "Educación y Saberes", en Filosofía de la Educación boy. Temas. V.V.A.A. Madrid: Ed, Dykinson, pp. 175-192.

Avanzini, G. (1990). La pedagogía desde el siglo XVII basta nuestros Días. México: FCE.

(1990). "La pedagogía de San Juan Bosco en su siglo”, en J. M. Prellezo. Don Bosco en la Historia (pp. 29I-298). Madrid: Editorial CCS.

Avanzini, Guy et al. (1996, 1998). La pedagogía boy. México: FCE.

Bosco, San Juan. (200I). Memorias del Oratorio de San Francisco de Sales. Edición crítica a cargo del P. Fernando Peraza Leal, sdb. Quito-Ecuador: Centro Salesiano Regional de Formación Permanente, 2001. 
Bourdieu, P. (1990). Sociología y cultura. México: Grijalbo-CNCA

Bowen, J. (I992). Historia de la Educación occidental. Tomo III, Barcelona, Editorial Herder.

Bowen, J. (1996). Teorías de la Educación. Innovaciones Importantes en el pensamiento educativo occidental. México. Noriega.

Braido, P. (1993). Breve Storia del "Sistema Preventivo.Roma: Librería Ateneo Salesiano (Piccola biblioteca dell Instituto Storico Salesiano). LAS-Roma.

et al. (I962). Educare. Sommario di Scienze Pedagogiche (a cura di Pietro Braido), Vol. I, Zürich.

Braido, Simonacelli, M, Gianolla et als. (I967) Educar. Salamanca: Sígueme.

Brunner, J.J. (1985). Estudios del campo científico VI. Los orígenes de la sociología profesional en Chile, Chile, FLACSO, núm. 38I.

Cassoti, M. Il método educativo di Don Bosco. Brescia. La Scuola I960. 89, en Braido, P. Breve Storia del Sistema Preventivo (p.89).

Cian, L. (1994). El sistema educativo de Don Bosco y las líneas maestras de su estilo. Madrid: Editorial CCS.

Chateau, J. (1974). Los grandes pedagogos. México: FCE.

De Tezanos, A. (2006). "Didáctica - pedagogía - ciencia de la educación: la relación que confirma la excepción francesa”. En Educación y Pedagogía, diciembre 46. Universidad de Antioquia, Facultad de Educación, (pp. 33-57).

(2007). "Formación de profesores: una reflexión y una propuesta”. En Pensamiento educativo, 4 I (2), 2007: 57-75.

Dilthey, W. (1940). Fundamentos de un sistema de Pedagogía. Argentina: Editorial Losada, S.A. (1968). Historia de la Pedagogía. Buenos Aires: Losada.

Fullat, O. (1998). "Epistemología de las Ciencias de la Educación", en V.V.A.A. Filosofía de la educación boy. Temas (pp. 15-30). Madrid: Dykinson. (I99I). "Educación", en Filosofía de la educación boy. Conceptos, autores, temas, V.V.A.A. Madrid: Ed. Dykinson, Cap. IV, pp. 68 - 90.

Flórez Ochoa, R. (2000). Hacia una pedagogía del conocimiento. Bogotá: McGRAW.

(2005). Pedagogía del conocimiento. Bogotá: McGraw -Hill Interamericana. 
Contexto pedagógico de Don Bosco. En torno a los antecedentes del sistema preventivo Juan Pablo Conejeros

Gimeno Sacristán, J; Pérez Gómez, A. (2002). Comprender y transformar la enseñanza. Madrid: Morata.

Gvirtz, S. y Palamidessi, M. (2002): El ABC de la tarea docente: Currículum y enseñanza. Tercera edición. B. Aires, Argentina: Grupo Aique.

Hargreaves, A. (1996). Profesorado, Cultura y Postmodernidad. Cambian los tiempos, cambia el profesorado. Madrid: Morata.

Luzuriaga, L. (I973). Historia de la Educación y de la Pedagogía. México: Losada, S.A.

Maritain, J. (1958). Arte y Escolástica, Club de Lectores, Buenos Aires (1955). Intuición creadora en el arte y la poesía (La poesía y el arte). Buenos Aires: Emecé editores, S.A.

Meylan, L. (1974). "Heinrich Pestalozzi (I746-I827)", en Chateau, J., Los grandes Pedagogos. México: F.C.E., pp. 203-2I8.

Mialaret, G. (I96I). Nueva pedagogía científica, Barcelona, Luis Miracles.

Rojas Moreno, I. "Presencia de los clásicos en la producción discursiva de pedagogía en la Facultad de Filosofía y Letras-UNAM”. Perfiles educativos [online]. 2006, vol.28, n.II3 [citado 2010-07-30], pp. 7-37. Disponible en: <http://www.scielo.org.mx/scielo.php?script=sci_ar ttext\&pid=SOI $8526982006000300002 \& \operatorname{lng}=\mathrm{es} \& \mathrm{nrm}=\mathrm{iso}>$. ISSN 0I85-2698.

Ortega Esteba, J. (1984). "Problemas teóricos y epistemológicos de la historia de la educación”, en Pedagógica Histórica. International journal of the History of Education, 24: I, I57-176.

Peraza, F. (2003). Iniciación al estudio de Don Bosco. Quito - Ecuador: CSR (Centro Salesiano Regional).

Perelló, J. (1995). Apuntes de Historia de la educación. Quito - Ecuador.

Pestalozzi, J. (1976). Cómo Gertrudis enseña a sus bijos, México, Porrúa ("Sepan cuantos...", 308).

Prellezo, J. M. (1997). Educar con Don Bosco. Ensayo de pedagogía salesiana. Madrid: Editorial CCS.

(Ed.).I990. Don Bosco en la Historia. Editorial CCS - Madrid.

Saavedra, M. (2005). Epistemología y Educación. Santiago de Chile. Universidad Arturo Prat.

V.V.A.A. (2009). Diccionario de Ciencias de la Educación. Roma: PUS. 